\title{
LA ÉTICA EN LA ERA DE LA TÉCNICA. ELEMENTOS PARA UNA CRÍTICA A KARL-OTTO APEL Y HANS JONAS
}

Paolo Becchi

Universidad de Génova

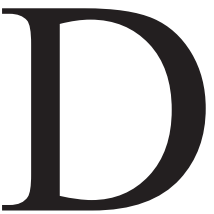

esde siempre la técnica ha acompañado la existencia del hombre sobre la tierra, pero mientras que en las épocas pasadas, la técnica permanecía de todos modos subordinada a la naturaleza, la época moderna se constituye sobre el radical vuelco de esta relación: la naturaleza se vuelve el campo ilimitado de la actividad transformadora del hombre, a la que está totalmente sometida. El modelo biomórfico propio del mundo antiguo es sustituido integralmente por el modelo mecánico.

Si para el propio modelo, magistralmente representado por el segundo libro de la Física de Aristóteles ${ }^{1}$, la téchne está subordinada a la phýsis y se le asigna la tarea de imitar (y en todo caso ayudar) a la naturaleza ${ }^{2}$, para el segundo modelo, que se remonta a la gran revolución científica del siglo diecisiete, la naturaleza se vuelve una gran máquina movida por conecciones causales y, una vez descubierto el mecanismo, el ser humano no está sólo en condiciones de de imitarla, sino que también la recrea con las propias manos y construye nuevas máquinas capaces de suplir sus defectos.

La naturaleza no es más, aristotélicamente, el fin dentro del cual se coloca el mismo actuar del hombre, sino que se nos aparece baconianamente

${ }^{1}$ Cfr. Aristóteles, Física, II (B), 1, trad. M. Boeri, A. Vigo, Bs. As. 1993/5. Al respecto véase el comentario de M. Heidegger, Vom Wesen und Begriff der physis. Aristoteles Physik B 1 (1940), en: Il pensiero III, 2, 1958, pp. 131-156 y III, 3, 1958, pp. 265-290: En los mismos números de la revista, en apéndice, es asimismo publicada la traducción italiana de G. Guzzoni.

${ }^{2}$ La técnica tiene, por tanto, una función complementaria respecto de la naturaleza: la ayuda a cumplir lo que la naturaleza no alcanza a lograr por sí sola. Cfr. en particular: Aristóteles, Protreptico, fr. 11 Ross. Sobre la relación naturaleza-téchne en la filosofía antigua, entre la literatura más reciente véase el ensayo de Enrico Berti, en el que viene bien deliniada la posición de Aristóteles. Cfr. Enrico Berti, "Il concetto di natura en la filosofia classica", en: Studium, 4-5, 1987, pp. 497-509. 
"constreñida y atormentada, removida a la fuerza de su estado ordinario y comprimida y forjada mediante el arte y el ministerio humano"s. Si para Aristóteles el hombre alcanza su propio fin y el de las cosas cuanto más se acerca a la naturaleza y la asume como modelo, para la concepción moderna vale exactamente lo contrario: todo lo que es natural debe ser reconducido a lo que es humano.

La naturaleza no es más un orden movido por fines, no hay en ella ninguna sacralidad que respetar y la técnica pierde aquella peculiar función de complementareidad respecto de la naturaleza, que había precedentemente. El advenimiento de la ciencia moderna prepara el terreno de este giro tecnológico: el temor que evocaban las misteriosas fuerzas naturales desaparece cuando su conocimiento exacto las revela. Pero recién la revolución industrial del siglo XIX completa el giro tecnológico de las ciencias naturales. Aquí se verifica aquella alianza que distingue al progreso moderno: el nuevo modo de relacionarse con la naturaleza, explícitamente teorizado por la ciencia moderna, deviene realidad concreta. Privada de toda aura, la naturaleza no era otra cosa que un objeto para someter a nuestro dominio.

En un primer momento ello ha comportado, para decirlo con Kant, la salida del hombre del estado de minoridad y la afirmación de su supremacía sobre la tierra. Pero al extenderse su poder se han alterado las relaciones con la naturaleza hasta el punto que hemos llegado, de poner en peligro su propia sobrevivencia sobre el planeta. Los hombres han pagado el acrecentamiento de su poder tecnológico no sólo con el extrañamiento de aquello sobre lo cual lo ejercitan, sino también con la destrucción de aquello que han aprendido a dominar. No pienso tanto en la amenaza nuclear, en un apocalipsis imprevisto que de un golpe borre de nuestro planeta la especie humana y otras formas de vida, sino más bien en un apocalipsis solapado (representado sobre todo por la crisis ecológica y por los riesgos conexos con la ingeniería genética) que hace avanzar el desierto en nosotros y fuera de nosotros día tras día sin que ni siquiera lo advirtamos.

La filosofía no podía pemanecer indiferente a estas transformaciones. $\mathrm{Y}$ es propio de aquél que, de un modo o de otro, puede ser considrado el más grande filósofo de nuestro siglo, Martín Heidegger, que trae la prime-

${ }^{3}$ Cfr. F. Bacone, Instauratio Magna (1623), trad. M. Granada, La Gran Restauración, Alianza, 1985.Sobre la gran transformación producida en el modo de pensar la naturaleza acaecida con el advenimiento de la ciencia moderna véase además la obra de A. Koyré, Dal mondo del pressapoco all universo della precisione (1948), Torino, Einaudi, 1967 (trad. esp. C. Solis Santos, México, s. XXI, 1992. Quisiera aquí recordar en particular: P. M. Schuhl, Mechanisme et philosophie, Paris, P.U.F., 1947. 
ra y más profunda contribución para una crítica filosófica de la técnica ${ }^{4}$. Heidegger, sin embargo, se ha limitado a constatar la dimensión teorética del peligro tecnológico y su génesis: esto es, él ha hecho visible el peligro, pero la vía para escapar del mismo se alejaba de la señalada por la ética. La combinación de "física y responsabilidad", de la cual no obstante habla en Unterwegs zur Sprache 5 , quedaba como una fórmula vacía, del todo inadecuada para la superación de la técnica. Bajo el perfil práctico, la actitud corresponsdiente era, para usar sus mismas palabras, una "Gelassenheit den Dingen", que más bien, en cierto sentido, parece casi presentarse como alternativa a una ética de la técnica.

El mérito de haber intentado mostrar el componente práctico de una filosofía de la técnica, una ampliación del campo realizada a través de la superación de Heidegger, corresponde a dos filósofos muy distintos entre sí, que buscan un fundamento para la ética en la época de la ciencia y de la técnica: Karl-Otto Apel y Hans Jonas ${ }^{7}$. El acercamiento de estos dos autores podrá,

${ }^{4}$ Cfr. M. Heidegger, Die Frage nach der Technik (1950), in Vorträge und Aufsätze, Pfullingen, G. Neske, 1962, trad.esp.Conferencias y artículos, Barcelona, Del Serbal.. Sobre el problema de la técnica en Heidegger, entre las lecturas más recientes, cfr. W. Schirmacher, Technik und Gelassenheit. Zeitkritik nach Heidegger, Freiburg-München, Alber, 1983; G. Seubold, Heideggers Analyse der neuzeitlichen Technik, Freiburg-München, Alber, 1986; la primera parte del ensayo recogida en W. Biemel, F. W. Herrmann (Hrsg.) Kunst und Technik. Gedächtnisschrift zum 100 Geburstag von Martin Heidegger, Frankfurt a.M., V. Klostermann, 1989. Con particular atinencia al problema de la relación entre técnica y ética véanse también las compilaciones de ensayos indicados en la nota 6.

${ }^{5}$ M. Heidegger, Unterwegs zur Sprache, Pfullingen, G. Neske, 1959 p. 210; trad esp. Barcelona, Del Serbal, 1990. Ya en su célebre Briefe über den Humanismus (1946) Heidegger había escrito: "Wir bedenken das Wesen des Handelns noch lange nicht entschieden genug". Pero también esta afirmación, más que señalar la apertura de Heidegger hacia la ética, expresaba solamente su propia perplejidad ante la posibilidad de una filosofía práctica.

${ }^{6}$ M. Heidegger, Gelassenheit, Pfullingen, G. Neske, 1960, en particular pp. 24-25.Trad. esp. Serenidad, Barcelona, Serbal, 1994. Confieso que no me convencen algunas tentativas recientes de relacionar la heideggeriana Gelassenheit a la discusión ética más reciente: W. Schirmacher (Hrsg.), Zeitkritik nach Heidegger, Essen, Blaue Eule, 1989 y R. Margreiter, K. Leidlmair (Hrsg.) Heidegger: Technik-Ethik-Politik, Würzburg, Königshausen \& Neumann, 1991. Las dificultades del intento de desarrollar una filosofía práctica a partir de Heidegger resultaba ya de una precedente colección de ensayos: A. Gethmann-Siefert, O. Pöggeler (Hrsg.) Heidegger und die praktische Philosophie, Frankfurt a. M., Suhrkamp, 1998.

${ }^{7} \mathrm{Mi}$ análisis crítico se concentra sobre estos dos autores, pero quizás vale la pena recordar que el problema de las relaciones entre técnica y ética en Alemania se encuentra en el centro de un interés creciente en los últimos años. Ya antes de Jonas, Sachsse, Technik und Ethik, Stuttgart, Reclam, 1989 (2) y K. Bayertz, "Wissenschaft, Technik und Verantwortung. Grundlagen der Wissenschafts- und Technikethik", in K. Bayertz (Hrsg.) Praktische Philosophie. Grundorientierungen angewandter Ethik, Reinbek bei Hamburg, Rowohlt, 1991, pp. 173-209. Para una consideración de conjunto sobre las diversas posiciones emergentes del debate es útil el reciente volumen de C. Walther, Ethik und Technik. Grundfragen-Meinungen-Kontroversen, Berlin-New York, W. de Gruyter, 1992. 
a primera vista, sorprender: la ética de la comunicación de Apel parece, en realidad, tener poco que ver con la ética de la responsabilidad de Jonas. Por otra parte, Apel ha declarado explícitamente que no comparte la propuesta filosófica de Jonas sobre un retorno a una fundamentación metafísica de la ética ${ }^{8}$, mientras que este último, por su lado, aún sin haberse ocupado nunca específicamente de la ética de la comunicación, parece considerarla bastante lejana de su propia posición filosófica ${ }^{9}$. Y a pesar de esta recíproca toma de distancia, es significativo observar cómo Apel reconoce una sustancial afinidad con Jonas en torno a la necesidad de elaborar una ética de la técnica. También para él, como veremos en breve, se necesita hablar de una ética de la ciencia y de la técnica, desde el momento en que ambas presuponen una ética como condición de posibilidad.

En las siguientes páginas no intento formular una presentación de conjunto de las dos perspectivas y su comparación ${ }^{10}$, sino que me limitaré a mostrar cómo Apel propone una ética de la técnica y a formular una objeción a su enfoque. En un segundo momento intentaré mostrar que la misma objeción puede hacérsele a Jonas. El presente intento no es reconstructivo, sino eminentemente crítico: aunque afronto un aspecto específico, pienso que éste es central en las elaboraciones de las concepciones filosóficas de ambos autores.

El punto de partida de la reflexión de Apel está dado por la situación paradojal en la que se encuentra la ética en la época de la ciencia ${ }^{11}$. Por un lado, los enormes desarrollos tecnológicos y científicos han acrecentado desmesuradamente la responsabilidad de los hombres, volviendo urgente la necesidad de una nueva ética. Por otro lado, la ciencia misma parece hacer imposible la

${ }^{8}$ Cfr. K.-O. Apel, "Verantwortung heute-nur noch Prinzip der Bewahrung und Selbstbeschänkung oder immer noch der Befreiung und Verwirkung von Humanität?” (1986), in: K. O. Apel, Diskurs und Verantwortung. Das Problem des Übergangs zur postkonventionellen Moral, Frankfurt a. M., Suhrkamp, 1990, pp. 179-216.

${ }^{9}$ (Considerando) al menos algunos pasajes referentes a la ética del discurso contenidos en una de sus últimas entrevistas:'De la gnose au 'Princìpe responsabilité'. Un entretien avec hans Jonas", en: Esprit, 1991, pp. 5-21 (21).

${ }^{10}$ Por otra parte, ya ha sido hecho un trabajo de este tipo, motivado por la aceptación de la perspectiva de Apel. Cfr. W. Kuhlmann, "Prinzip Verantwortung versus Diskursethik", en: Archivio di filosofia, LV, 1987, 1-3, pp. 89-116.

${ }^{11}$ El ensayo fundamental de Apel (para el problema que aquí interesa) sigue siendo "Das Apriori der Kommunikationsgemeinschaft und die Grundlagen der Ethik. Zum Problem einer rationalen Begründung der Ethik im Zeitalter der Wissenschaft”, en: K.-O. Apel, Transformation der Philosophie, Bd. 2: Das Apriori der Kommunicationsgemeinschaft, Frankfurt a. M., Suhrkamp, 1973, pp. 358-435 (hay trad. de A. Cortina, J. Chamorro y J. Conill, Transformación de la filosofia, Madrid, Taurus, 1985). Para una sucinta presentación de la perspectiva de Apel es útil el reciente volumen K.-O. Apel, Etica della comunicazione, Milano, Jaca Book, 1992. 
investigación de un fundamento racional de la ética: en primer lugar, porque se considera a la ciencia como libre de valores (según Max Weber wertfrei), en segundo lugar, porque la racionalidad está determinada por la ciencia. Si la racionalidad avalorativa de la ciencia es el paradigma de la racionalidad filosófica, entonces la demanda de una ética universalmente vinculante no puede ser satisfecha. Por lo tanto, aquí está delineado el carácter paradójico de la situación problemática"12 de la ética contemporánea: mientras que, por una parte, la ciencia con sus aplicaciones técnicas nos enfrenta a la necesidad de una nueva ética, por otra parte, ella misma (por cómo ha sido concebida) parece hacer imposible una fundación racional de la ética. De ello resulta lo que Apel llama "sistema de complementareidad" entre positivismo científico y existencialismo irracionalista. La idea de objetividad científica libre de valores relega los valores y las normas de la moral al grado de los sentimientos irracionales o las decisiones arbitrarias también irracionales: brevemente, a elecciones privadas como la pertenencia a esta o aquella confesión religiosa ${ }^{13}$.

Cientismo y decisionismo éticos son, por lo tanto, sólidamente complementarios entre sí y ambos son opuestos a una fundamentación racional última de principios morales universales. Justamente, a esta Letzbegründung apunta Apel con su ética de la comunicación. Reducido a términos mínimos, el razonamiento es el siguiente. No se puede negar ciertamente que la ciencia sea necesariamente avalorativa en relación con el objeto que estudia: las ciencias de la naturaleza describen su objeto y no pueden prescribir nada. Pero sería equivocado pensar que los científicos tienen también en sus relaciones mutuas una actitud avalorativa. Por el contrario, la condición de posibilidad de la ciencia misma es que haya al menos para la comunidad de los cientificos un fundamento ético: esta comunidad presupone el reconocimiento recíproco de los sujetos interesados en el conocimiento científico. Remitiéndose a consideraciones ya formuladas por Charles S. Pierce y más recientemente por Kuno Lorenz, Apel hace propia la idea según la cual "la lógica - y al mismo tiempo con ella todas las ciencias y las tecnologíaspresuponen como condición de posibilidad una ética"14.

${ }^{12}$ K.-O. Apel, Das Apriori der Kommunikationsgemeinschaft...cit. p. 359.

${ }^{13}$ Ivi, pp. 361-362. En esta perspectiva, lo que es normativamente vinculante remite a "una elección de la razón misma (genitivo objetivo!) la cual no es fundamentable mediante algún criterio racional, y puede entonces resultar también (entretanto) contra la razón y por esto contra la moral de la responsabilidad". Cfr. K. -O. Apel, Il problema della fondazione di un 'etica della responsabilitá nell ' epoca della scienza, in: E. Berti (a acura di ), Tradizione e attualità della filosofía pratica, Genova, Marietti, 1988, pp. 15-45 (19).

${ }^{14}$ K.-O. Apel, Das Apriori der Kommunikationsgemeinschaft... cit., p. 399. En una nota a pie de página Apel remite a Konrad Lorenz, "Die Ethik der Logik", en H.-G. Gadamer, (Hrsg.) Das Problem der Sprache, Achter Deutscher Kongreß für Philosophie), München, W. Fink, 1967, pp. 80-86. 
No podemos argumentar racionalmente sobre ningún tema, si no presuponemos además de una determinada estructura de la realidad y de las reglas lógicas, también una serie de normas éticas. Y ello por el hecho de que no es posible controlar la validez lógica de los argumentos sin presuponer una comunidad de científicos capaces de comunicación lingüística y de producir un consenso intersubjetivo ${ }^{15}$.

Todo tipo de conocimiento es entonces público a priori, lo que implica que uno en soledad no puede procurar validez a su razonamiento. Ello implica que toda ciencia y, en sentido lato, toda argumentación, presupone una ética y que no puede privarse del reconocimiento recíproco de las personas como sujetos de la argumentación. Ninguna argumentación, entonces, puede ser comprendida recurriendo a la mera dimensión sintáctico-semántica del lenguaje, sino que toda argumentación implica una dimensión pragmática, una pretensión de validez que se puede explicar solamente en el diálogo interpersonal ${ }^{16}$.

Ahora bien, aún admitiendo que este razonamiento sea convincente, de ello sin embargo no se sigue todavía que el fundamento normativo de la lógica y de la ciencia pueda reivindicar alguna obligatoriedad moral (a menos que no se quiera considerar como un deber moral la misma investigación de la verdad). Apel muestra solamente que nosotros hemos reconocido ya siempre las normas morales en el momento en el cual discutimos en torno a cualquier pretensión de validez. En este sentido puede concordarse con él cuando opina que la fórmula un poco vaga de "ética de la lógica" expresa algo correcto ${ }^{17}$. El problema, sin embargo, consiste en establecer en qué relación se encuentra esta ética, esta base normativa presupuesta de la ciencia misma, con aquello que normalmente entendemos por ética. La argumentación en el ámbito ético no está en realidad dirigida a la investigación de la verdad, como en el caso de la ciencia, sino más bien al fundamento de validez de normas para la acción.

\footnotetext{
${ }^{15}$ Con palabras de Apel: "No se puede controlar la validez lógica de los argumentos sin presuponer una comunidad de pensadores capaces de comunicación y de la formación de consenso intersubjetivo. También el pensador solitario de hecho puede explicar y controlar su argumentación sólo en cuanto es capaz de interiorizar, en el "coloquio" crítico "del alma consigo misma” (Platón), el diálogo de una potencial comunidad de argumentación” (ibid.).

${ }^{16}$ Este aspecto ha sido desarrollado por los dos discípulos más conocidos de Apel. Cfr. D. Böhler, Rekonstruktive Pragmatik. Von der Bewußtseinsphilosophie zur Kommunikationsreflexion: Neubegründung der praktischen Wissenschaft und der Philosophie, Frankfurt a. M., Suhrkamp, 1985; y W. Kuhlmann, Reflexive Letztbegründung. Untersuchungen zur Transzendentalpragmatik, Freiburg-München, Alber, 1985.

${ }^{17}$ K.-O. Apel, Das Apriori der Kommunikationsgemeinschaft... cit., p. 423.
} 
También Apel esta dispuesto a admitir que una "ética de la lógica" no es suficiente para fundar una ética de la comunicación humana y, sin embargo, cuando afronta este último aspecto, toda su argumentación se presenta simplemente como una generalización del enfoque que vale para el modelo de la comunidad de comunicación entre los científicos. Lo que en la filosofía no podemos eludir es el pensamiento y si se considera al pensamiento, de modo no solipsista, se deberá admitir que quienquiera que piense seriamente (cualquier ser humano que sea capaz de razonar) ya forma parte de una comunidad de comunicación. En realidad si él argumenta seriamente deberá continuamente dirigirse a una comunidad de comunicación capaz de controlar la validez de sus argumentos y de formar consenso sobre sus pretensiones de validez.

Siguiendo este razonamiento Apel llega a la conclusión que nosotros -no en cuento científicos, sino simplemente en cuanto seres humanos racionales- debemos haber reconocido ya siempre la existencia de determinadas normas éticas fundamentales. Así como, quien argumenta seriamente ha aceptado necesariamente el punto de vista de la razón y se chocaría con una contradicción pragmática, si encontrándose ya sobre el terreno del discurso argumentativo, desconociese la validez universal de las reglas del discurso, del mismo modo quien solamente se pregunta si hay algo como una norma universalmente válida, se encuentra ya sobre el terreno del discurso argumentativo ético y con ello ha reconocido necesariamente que forma parte de la comunidad de comunicación.

Las reglas que nosostros debemos seguir para alcanzar el conocimento no son distinguidas por Apel de las normas éticas que se presume que nosostros reconocemos si queremos vivir con otros seres humanos. Él pretende resolver el problema de la fundamentación de las normas morales extendiendo las reglas de la argumentación teorética a las normas del obrar práctico. Esto es, él tiende a deducir las normas vinculantes del obrar práctico de las consdiciones del uso de nuestro intelecto, cayendo así en aquello que Karl-Heinz Ilting - justamente en polémica con Apel- definió como "falacia intelectualista"18.

${ }^{18}$ Cfr. K. H. Ilting, "Der Geltungsgrund moralischer Normen”, en: D. Böhler, W. Kuhlmann (Hrsg.), Kommunikation und Reflexion. Festschrift für Karl-Otto Apel, Frankfurt a.M., Suhrkamp, 1982, pp. 612-648 (612): “Como falacia intelectualista quisiera definir el intento de deducir normas vinculantes a partir de las condiciones del uso de nuestro intelecto o de descubrir el fundamento del valor de su obligatoriedad en el ámbito de estas condiciones. Tal intento es falaz, por el hecho de que las reglas que nosotros debemos seguir para alcanzar el conocimiento son confundidas con aqullas normas que se presume que nosotros reconocemos si queremos vivir juntos en relaciones ordenadas, sea desde el punto de vista jurídico o desde el punto de vista moral. Si aquellas reglas no son en absoluto vinculantes del mismo modo en el 
También Apel transgrede entonces la ley de Hume, si se observa-como Francesco Fagiani ha recordado oportunamente en uno de sus últimos trabajos- que Hume además de sancionar el fin del "naturalismo ético" critica radicalmente al "racionalismo ético"19. El intento de Apel es falaz en este último sentido, poque él piensa que la fundamentación de las normas éticas puede ser encontrada en la corrección de una argumentación racional. Pero también si se admite -sieguiendo su razonamiento- que quien habla de ética se ha ubicado ya sobre el terreno del discurso argumentativo ético, con ello no hemos dicho todavía nada decisivo sobre el fundamento de validez de las normas que debemos seguir para actuar de modo responsable.

De la corrección de una argumentación por sí misma no surge ninguna norma y tanto menos puede fundarse sobre esa corrección solamente la obligación de reconocerla. Para aquel que no la acepta, no subsiste ni siquiera la obligación de seguirla: del hecho de mostrarle que discutiendo la obligatoriedad de determinadas normas las ha reconocido implícitamente, no se deriva que para él tales normas sean también efectivamente vinculantes. En este caso, la remisión a la presencia de una contradicción performativa al nivel del lenguaje no me parece de particular relevancia, en cuanto el hecho de situarse sobre el terreno del discurso argumentativo no implica todavía la elección de seguir determinadas normas éticas ${ }^{20}$.

Una voluntad libre es libre también de no reconocer reglas morales fundamentales y de decidirse por el mal. Esta decisión no comporta - como parece creer Apel- la pérdida del uso de la razón, sino solamente la renuncia a una determinada "autocomprensión", la propia del discurso moral. En suma, quien comete un homicidio, no por ello debe ser considerado necesariamente un enfermo mental. Entonces, aunque admitimos que quien obra presupone normalmente haber reconocido normas morales, este reconocimiento presupuesto no constituye de por sí una condición suficiente para explicar la universal obligatoriedad moral de estas normas.

que lo son las normas morales, todo tentativo de fundar la obligatoriedad de las normas mediante el recurso a las reglas del uso de nuestro intelecto debe fallar". Este texto se encuentra ahora comprendido en la colección de ensayos de K. -H. Ilting, Grundfragen der praktischen Philosophie, en:. V. P. Becchi /. H. Hoppe (Hrsg), Frankfurt a. M., Suhrkamp, 1994, pp. 138-175.

${ }^{19}$ Cfr. F. Fagiani, "Etica e teorie die diritti”, en: C. A.Viano (ed.), Teorie etiche contemporanee, Torino, Bollati Bollinghieri, 1990, pp. 87-107.

${ }^{20}$ Esta objeción ha sido ya formulada desde muchas perspectivas y con finalidades diversas contra Apel: Cfr., por ejemplo, J. Habermas, Moralbewußtsein und kommunikatives Handeln, Frankfurt a. M., Suhrkamp, 1983, pp. 96 y 109 (trad. esp. Conciencia moral y acción comunicativa, Barcelona península, 1998); E. Castrucci, Considerazioni epistemologiche sul conferimento di valore, Firenze, S. Gallo, 1988, p. 15; H. Hoppe, "Normenbegründung ohne naturalistische Fehlschuß?”, in K.-O. Apel/R. Pozzo (Hrsg.), Zur Rekonstruktion der praktischen Philosophie. Gedenkschrift für Karl-Heinz Ilting, Stuttgart - Bad Cannstatt, FrommannHolzboog, 1990, pp. 226-245 (239). 
Para Apel, en cambio, la obligación moral se reduce a un mero objeto de cogniciones de reglas del juego que son ineludibles, tanto que para entender a quien se opone a ellas necesita hacer referencia a una situación psicopatológica ${ }^{21}$. Él,entonces, no hace otra cosa que extender el principio de la fundamentación filosófica (según el cual el argumentar y sus reglas son condiciones intrascendibles para la misma posibilidad de argumentar) al principio ético-normativo. El aseguramiento de la intrascendibilidad argumentativa de la razón deviene así no sólo el principio de una fundamentación de la racionalidad (alternativa al cientismo avalorativo), sino del mismo modo el principio de la fundamentación de la ética.

La fundamentación de las normas morales no resulta entonces de las condiciones de un obrar moralmente responsable, sino de las condiciones de la argumentación racional. Sin embargo, quién argumentando para solucionar cualquier problema comete un error, no por ello obra de modo inmoral. Quien viola las reglas de la argumentación racional obra precisamente irracionalmente y si lo hace a propósito, obra de modo absurdo: no por ello, sin embargo obra de modo reprobable. En suma, las reglas de la argumentación y las normas éticas son reglas de tipo diferente, tanto que quien viola las primeras se comporta de modo irracional, mientras que quien viola las segundas se comporta de modo reprobable. Los presupuestos implícitos de una argumentación racional se fundan sobre el esfuerzo común de los argumentantes. Este esfuerzo tiende a resolver un determinado problema de modo racional: ellos, entonces, no contienen ninguna norma moral vinculante, sino que, en el sentido de Kant, sólo son imperativos hipotéticos racionalmente condicionados por el objetivo que ya estaba prefijado (la correcta solución de un problema) ${ }^{22}$.

Consideremos un poco más de cerca la distinción entre imperativos hipotéticos y categóricos tal como ha sido presentada por $\mathrm{Kant}^{23}$. Según los primeros, una acción es buena según el fin que sea prefijado: ella es considerada como un medio para alcanzar alguna otra cosa. Para los segundos, en

\footnotetext{
${ }^{21}$ Precisamente, Apel afirma que quien se pone fuera de la comunidad de comunicación "renuncia así, al mismo tiempo, a la posibilidad de la autocomprensión y de la autoidentificación". Y en nota precisa que "esto se puede...confirmar en el sentido de la psicopatologíoa clínica”. K.-O. Apel, Das Apriori der Kommunikationsgemeinschaft... cit., p. 414.

${ }^{22}$ Éste es, en substancia, el sentido de la objeción formulada por Ilting contra Apel: Cfr. Der Grundlegung moralischer Normen, cit., en particular: pp. 622-627

${ }^{23}$ Cfr. I. Kant, Grundlegung zur Metaphysik der Sitten (1785), en I. Kant, Werke in zehn Bänden, hrsg. Von W. Weischedel, Darmstadt, Wissenschaftliche Buchgesellschaft, Vol. 6, pp. 43-46 ( hay trad. de M. García Morente, Fundamentación de la metafísica de las costumbres, Madrid, Espasa Calpe, 1946.). Véase también I. Kant, Kritik der Urteilskraft (1790), en Werke in zehn Bänden, cit., vol. 8, pp. 241-243 (hay trad. de José Rovira Armengol, Crítica del juicio, Buenos Aires, Losada $3^{\mathrm{a}}$, 1993.).
} 
cambio, la acción es buena en sí misma, vale decir independientemente de las condiciones para alcanzar cualquier otro objetivo. A su vez, los imperativos hipotéticos son distinguidos por Kant en problemáticos y asertóricos. Los primeros, dictados técnicos o de habilidad, no se preguntan sobre la racionalidad o la bondad de los fines, sino solamente sobre qué debe hacerse (esto es, qué medios deben aplicarse) para alcanzarlo. Bajo este perfil -son ejemplos de Kant- las prescripciones de un médico para curar a un ser humano o las de un envenenador para asesinarlo tienen el mismo valor porque ambas son medios adecuados para alcanzar el fin prefijado. Los segundos, dictados pragmáticos o de la prudencia, presuponen la determinación de un fin, la felicidad, y el imperativo consiste en la elección de los medios más idóneos para obtener ese fin determinado. Si bien Kant distingue el concepto de habilidad (Gechicklichkeit) del de prudencia (Klugheit), en ambos casos nos encontramos frente a principios que no son atinentes a la esfera ética. Según Kant, ni los imperativos técnicos ni los pragmáticos pueden ser definidos como morales, porque -sea que se deba determinar el fin cada vez (como en los primeros), sea que el fin se encuentre presupuesto (como en los segundos)- el obrar no es prescripto como fin en sí mismo, sino siempre como medio para otro objetivo. Las reglas de la habilidad y de la prudencia, más allá de sus diferencias, representan entonces tipos de racionalidad estratégica respecto del objetivo que no son comprendidas por la esfera ética. Con su propuesta de una ética de la comunicación, Apel se detiene, entonces, más acá de una adecuada fundamentación de la ética, porque ella en realidad no ofrece otra cosa que la fundamentación de normas hipotéticas.

Las reglas del discurso argumentativo valen sólo si por medio del discurso se quiere alcanzar la verdad. Ellas valen entonces como presupuesto instrumental de ese particular tipo de racionalidad respecto de ese objetivo que es el dicurso; vale decir que valen si se quiere argumentar en torno a las pretensiones de verdad y validez. Así, por ejemplo, la inadmisibilidad de la mentira es fundamentada por Apel recurriendo al objetivo prefijado por esas reglas: "mentir haría imposible el diálogo entre los argumentantes"24. Pero una mentira podría ser inadmisible en vista del objetivo del discurso -el discurso argumentativo tiene como objetivo el logro de la verdad-, sin ser por ello de por sí moralmente reprobable. Al contrario, en ciertos casos, bajo el aspecto moral, el no decir la verdad puede ser lícito (cuando, por ejemplo, se le oculta a un paciente la verdad sobre su enfermedad, suponiendo que si se obra de otro modo se puede agravar su cuadro) o puede ser directamente obligatorio (cuando diciendo una mentira se evita traicionar a un inocente).

\footnotetext{
${ }^{24}$ K.-O. Apel, Das Apriori der Kommunikationsgemeinschaft... cit., p. 400.
} 
La mentira deviene moralmente reprobable sólo en el momento en que sirve para abusar de la confianza de otro y se la utiliza para lograr fines egoístas o directamente malvados. En suma, propiamente el modo en que Apel afronta el problema de la mentira confirma que las reglas de la argumentación no contienen ninguna norma moral vinculante, sino solamente imperativos hipotéticos condicionados por la racionalidad del objetivo del discurso.

Apel ha intentado replicar a esta crítica ${ }^{25}$ sosteniendo que no se puede definir al discurso argumentativo como una empresa cualquiera de cooperación respecto del objetivo, en la cual los seres humanos se pueden comprometer más o menos. En la investigación discursiva de la verdad, todos los hombres, en cuanto seres racionales estarían necesariamente comprometidos. Por esta razón, el tipo de racionalidad discursiva se distingue del tipo de racionalidad técnico-instrumental: sus reglas son categóricamente vinculantes y no apuntan a la solución de una finalidad contingente. Sin embargo, de este modo Apel presupone lo que quiere demostrar. No existe una obligación, válida para todos, de comprometerse en la realización de determinados objetivos y mucho menos existe algo como una obligación universal a participar en una comunidad de comunicación. Cada uno debe ser libre de decidir si quiere comprometerse en una empresa de ese tipo o no. Lo relevante es esta decisión libre de cada uno y no los motivos por los cuales decide comprometerse o no, o si estos motivos valen para algunos, muchos o directamente para todos los hombres. Entonces, la participación en la comunidad de comunicación no es otra cosa que el objetivo de una acción.

Apel intenta impedir esta conclusión replicando que el discurso argumentativo no es comparable a cualquier objetivo que los individuos puedan arbitrariamente elegir o no elegir, porque se trata de un "objetivo a priori común" 26 , por así decir elegido necesariamente ya siempre por todos, siendo

${ }^{25}$ En un largo y complicado ensayo en lengua alemana, pero publicado en una revista italiana: K.-O. Apel, "Lässt sich ethische Vernunft von strategischer Zweckrationalität unterscheiden? Zum Problem der Rationalität sozialer Kommunikation und Interaktion”, en: Archivio di Filosofia, LI (1983), nr. 1-3., pp. 375-434 (en particular pp. 416-422). Ilting responde a Apel con una carta privada, datada el 28 de noviembre de 1983, en la cual repite su crítica, considerándola no afectada por la objeción de Apel. Una respuesta pública, si bien indirecta a Apel se encuentra en un ensayo publicado póstumo en lengua castellana. "Qué significa propiamente 'moral'?", en: Cuadernos de ética, vol. 1, n 1, (1986), pp. 47-65. El original alemán se encuentra ahora publicado en: K.-H. Ilting, Grundfragen der praktischen Philosophie, cit., pp. 339-356.

${ }^{26}$ Cito el pasaje entero de Apel: "Con ello, de hecho está fijado un objetivo común de los participantes del discurso; pero esto no deriva de un objetivo cualquiera que es posible elegir a partir de los intereses empíricos de los otros, sino más bien a partir del objetivo a priori común de la formación de consenso sobre pretensiones de validez" (K.-O. Apel, "Lässt sich ethische Vernunft von strategischer Zweckrationalität unterscheiden?”, cit. , p. 418). 
la condición misma de la posibilidad de la realización de un pensamiento intersubjetivamente válido. Tampoco esta observación parece particularmente relevante: el hecho que el objetivo sea arbitrariamente elelgido o sea más bien algo hacia lo cual todos necesariamente aspiran, cambia muy poco el carácter de las reglas del discurso. Ellas siguen siendo, no obstante, condiciones necesarias para el logro del objetivo y, en cuanto tales, imperativos hipotéticos. Dado que el objetivo de la acción no es algo a lo que el individuo puede aspirar, sino más bien algo a lo que todos deben necesariamente tender, tales imperativos, en vez de ser problemáticos, serían como mucho asertóricos, pero no obstante siempre hipotéticos y no categóricos. Siguiendo el enfoque de Apel, entonces, se alcanza a fundar las reglas de la habilidad o como mucho las de la prudencia, pero no las reglas propiamente morales.

Veamos en qué sentido esta objeción puede ser dirigida también hacia una concepción como la de Jonas, que indudablemente está muy lejana del tipo de fundamentación intelectualista aquí considerada.

\section{II}

Todo el razonamiento de Jonas a favor de una ética de la técnica se funda sobre la siguiente premisa: la técnica es el ejercicio de un poder humano, esto es, una forma del obrar y todo obrar humano está expuesto a un examen moral $^{27}$. Ya en esta primera cadena asociativa se esconde un equívoco de fondo. Que la técnica sea una forma del obrar humano no necesita ser demostado, pero que ella, por esa razón, esté de por sí sujeta a consideraciones de naturaleza ética es menos obvio de lo que Jonas quisiera dar a entender.

El trabajo de la tierra y la producción de mercancías, por ejemplo, son indudablemente formas del obrar humano que implican un determinado desarrollo de la técnica y están sujetas a transformaciones a causa del descubrimiento de nuevas tecnologías. Sin embargo, estas actividades en cuanto tales no se nos presentan inmediatamente (por lo menos) como objeto de un interés ético. En ambos casos, nos encontramos sobre todo con actividades productivas dirigidas a la realización de determinados objetivos. Lo que tenemos frente a nosostros es un estado de cosas a transformar: el campo para arar y la producción de objetos de materia inorgánica. La técnica es el saber que guía este género de actividad. Pero se trata de un saber y de una actividad

${ }^{27}$ Cfr. H. Jonas, Das Prinzip Verantwortung. Versuch einer Ethik für die technologische Zivilisation, Frankfurt a. M., 1979, (hay trad. de J. M. Fernández Retenaga, El principio de responsabilidad. Ensayo de una ética para la civilización tecnológica, Barcelona, Herder, 1995) y H. Jonas, Technik, Medizin und Ethik. Zur Praxis des Prinzips Verantwortung, Frankfurt a. M., Suhrkamp, 1985 (Hay trad. esp. de C. Fortes Gil, Técnica, medicina y ética. Sobre la práctica del principio de responsabilidad, Barcelona, Paidós, 1997. 
diversos del saber ético que se propone como guía del obrar moral. Es cierto que también el obrar moral puede implicar un hacer orientado a un objetivo, pero en este caso la actividad con vista a fines es secundaria respecto de otro aspecto que deviene, en cambio, de primera relevancia. Cuando los hombres mismos devienen objeto de una actividad dirigida a la realización de determinados objetivos, lo implicado en esta actividad no es simplemente el objeto de tal realización, sino el sujeto que puede pretender dar o no dar su consentimiento. Quien debe sufrir una intervención quirúrgica, por ejemplo, es llamado a dar su consentimiento y sin ello no puede ser sometido a la operación. En este caso la actividad no atiende primeramente a un estado de cosas a modificar, sino al consentimiento efectivo o presunto de quien está implicado en ella. A esto último se subordina el mismo obrar dirigido a la realización de un fin del todo defendible, como el de la salud del paciente.

La distinción aquí ilustrada entre dos diversos tipos de obrar con características específicas tiene por su parte una larga tradición ${ }^{28}$. Por ciertos aspectos, ella permite, desde luego, conjugar concepciones éticas muy distantes entre sí, como las de Aristóteles y Kant. Ella se acerca, en efecto, tanto a la distinción aristotélica entre praxis (y el saber que la orienta, la phrónesis) y póiesis ( y el saber relativo a ella, la téchne), como a la distinción kantiana entre imperativos categóricos (propios de la moral) e imperativos hipotéticos, técnicos (propios de todo arte) o pragmáticos (que se refieren al bienestar general).

Justamente, esta importante distinción falta en la teoría de Jonas. No se trata en absoluto de negar una trama de técnica y ética, pero Jonas la vuelve a tal punto inestricable, que los hilos de la obligatoriedad moral no pueden distinguirse ya de los hilos de la necesidad técnica. Jonas cree corregir a la técnica, pero no se da cuenta de que al mismo tiempo diluye la fuerte esencia de la moral. En el fondo, lo que él nos presenta no es una nueva ética, sino más bien una serie de indicaciones, inspiradas en una sabia (y antigua) prudencia, que nosotros deberíamos seguir en la realización de nuestros objetivos.

Muchas de las indicaciones de Jonas sobre los diversos temas de bioética que él afronta ${ }^{29}$ son, a mi parecer, ampliamente compartibles, pero ello no

${ }^{28}$ Ella es retomada y reactualizada por K. H. Ilting en un ensayo que ha pasado totalmente desapercibido: K. -H. Ilting, "Tecnica e prassi in Heidegger e Marx", en: Metaphorein, 2-4, 1979, pp. 100-108. (E1 original alemán esta ahora publicado en: K.H. Ilting, Grundfragen der praktischen Philosophie, cit., pp. 326-336). Aquí Ilting contra Marx y Heidegger establece una distinción entre actividad práctica y actividad productiva que se acerca a la distinción aristotélica entre praxis y póiesis, a pesar de no identificarse con ella.

${ }^{29}$ Véanse sobre todo los ensayos 6-11 contenidos en el volumen Technik, Medizin und Ethik, cit., pp. 109-268. Cfr. también: Philosophical Essays. From Ancient Creed to Technological Man, Chicago, The University of Chicago Press, 1974. En particular los ensayos 5-7. 
impide el déficit que presenta su construcción ética. A través de ella, él no alcanza - como cree- el nivel de la incondicionalidad del imperativo categórico, sino que se detiene en ese nivel inferior de los imperativos hipotéticos: éstos se derivan de la técnica y no de la moral ${ }^{30}$.

Las reglas morales no pueden ser adecuadamente expresadas en la relación medio-fin, desde el momento en que no se refieren inmediatamente ni a determinar fines ni a aplicar medios. Que la utilización de un medio sea moralmente lícita o no, no depende del fin que con ese medio se intenta perseguir, sino en última instancia de la posibilidad de recurrir al consenso efectivo o presunto de aquellos que están interesados en el uso de aquél medio.

La moral no puede eludir este obstáculo y un problema técnico no puede dejar de ser examinado sobre todo técnicamente; esto es: no se puede pensar que la moral resuelva las questiones abiertas por la técnica, sino que de la técnica misma deben surgir las respuestas a los problemas que ella produce. Si un medio es inadecuado para alcanzar un determinado objetivo, lo que nos permita alcanzarlo no será ante todo la moral, sino el descubrimiento de otro medio.

Por otra parte, el propio Jonas admite que la técnica misma necesita obtener los remedios para sus enfermedades ${ }^{31}$. El pánico apocalíptico -él

\footnotetext{
${ }^{30}$ Por otra vía, también Maria Chiara Pievatolo llega a esta conclusión en un ensayo tan crítico como estimulante. A diferencia de la joven autora, no me parece, sin embargo, que se pueda negar la situación cualitativamente nueva frente a la que nos ubica el actual desarrollo tecnológico. (Cfr: M.C. Pievatolo, "Hans Jonas: un“ etica perla civiltà tecnologica", en: Il Politico, LV, n. 2, pp. 337-349). Pero también si se admite esa tesis, no creo que de ella se siga que la ética pueda reducirse a una ética de la técnica. Entre estos dos términos puede haber complementaridad pero no identificación. De otro modo, se corre el riesgo de perder aquello que distingue a la ética (también respecto de la técnica). Por esta razón, no me convencen todas aquellos intentos que afrontan el problema moral partiendo de una filosofía de la técnica. Al respecto, son ejemplares los trabajos de Hans Lenk, de los cuales me limito a recordar aquí sólo una reciente complilación de ensayos: H. Lenk, Zwischen Wissenschaft und Ethik, Frankfurt a. M., Suhrkamp, 1992.

${ }^{31}$ Jonas está bien lejos de aquella demonización de la técnica que encontramos, por ejemplo, en los escritos de Günther Anders. No se trata de detener el progreso tecnológico, sino de guiarlo mediante una "ética de la autolimitación". Para una referencia explícita a Anders de parte de Jonas Cfr. H. Jonas, Philosophie. Rückschau und Vorschau am Ende des Jahrhunderts, Frankfurt a. M., Suhrkamp, 1993, pp. 29-30 (trad.it. a cura di C. Angelino, La filosofia alle soglie del duemila. Una diagnosi e una prognosi, Genova, il Melangolo, 1994). Sobre las diferencias entre Jonas y Anders cfr. P. P. Portinaro, "Il profeta e il tiranno. Considerazioni sulla proposta filosofica di Hans Jonas", en: Nuova Civiltà delle Macchine, X, 1, (37), 1992, pp. 100-111. Sobre estos temas y más en general sobre la relación hombre-naturaleza, véase la reciente compilación de entrevistas, publicada postumamente: H. Jonas, Dem bösen Ende näher. Geschpräche über das Verhältnis des Menschen zur Natur, hrsg. V. W. Schneider, Frankfurt a. M., Surhkamp, 1993.
} 
nos advierte en Technik, Freiheit und Pflicht- no "nos podrá jamás hacer olvidar que la técnica es una obra de la libertad humana"32, que la aventura tecnológica no se puede interrumpir. Del punto en el que nos encontramos no se regresa y avanzar acarrea siempre nuevos peligros. La moral, entonces, debería enseñarnos a convivir con los altos riesgos a los que nos expone la técnica.

En ello reside la esencia de la ética de la técnica: un potente sedativo para calmar los delirios de la técnica. El punto es si la ética así entendida no se expone a la objeción que hemos formulado recién contra Apel. Ciertamente se podrá replicar que aquella objeción se mueve integralmente en el ámbito de la tradicional visión antropocéntrica de la ética (no casualmente toma impulso de la distinción entre objetos y personas implicados en una actividad con respecto a fines), mientras que Jonas sostiene que tenemos necesidad de una nueva ética capaz de superar aquel horizonte limitado. Y, además, se podrá agregar que ella parece no tener en cuenta la nueva relación del hombre con la naturaleza; la que nos ubica frente al actual desarrollo de la técnica, aspecto sobre el que Jonas insiste con particular fuerza.

Consideremos ante todo este último punto. Resulta difícil poner en cuestión el hecho que las intervenciones del hombre en la naturaleza se han extendido tanto como para exigir una respuesta ya no sólo técnica, sino también ética. Ahora resulta manifiesto el hecho de que el progreso tecnológico deja de ser una fuente de liberación del hombre y se transforma (o ya se ha transformado) en una maldición: el gran discurso actual sobre la crisis ecológica representa la toma de conciencia sobre este fenómeno.

Del mismo modo, en esta situación, resulta siempre más arduo sostener la tesis tecnocrática, según la cual las soluciones disponibles serían de naturaleza meramente técnica, desde el momento en que, como Jonas no se cansa jamás de repetir, son propiamente los desarrollos "buenos"de la técnica aquellos de donde surgen también los males más grandes. A la técnica moderna le es congénita una ambivalencia que la vuelve insidiosa también cuando está comprometida para alcanzar los objetivos que parecen totalmente legítimos. De esta perversa dialéctica no se sale entonces gracias a la técnica (o por lo menos con su sola ayuda).

En oposición al intento de afrontar exclusivamente con medios técnicos la aventura humana, el proyecto de una ética para la civilización tecnológica representa indudablemente una alternativa. El problema, sin embargo, es si

\footnotetext{
${ }^{32}$ Este discurso, pronunciado en ocasión del otorgamiento del premio de la paz por parte de los libreros alemales, ha sido publicado nuevamente en el volumen: H. Jonas, Wissenschaft als persönliches Erlebnis, Göttingen, Vandenhoeck \& Ruprecht, 1987, pp. 7-31 (trad. it. di F. Tomasoni, Scienza come esperienza personale, Brescia, Morcelliana, 1992, pp. 9-49.)
} 
resulta suficiente una ética de la técnica como la propuesta por Jonas para realizar tal proyecto. ¿En qué puede consistir una ética de la técnica? ¿Está ella en condiciones de ofrecer un punto de apoyo válido para la fundamentación de la ética?

Hablar de ética de la técnica permite, sin duda, una transformación de gran relieve en el modo de concebir la ciencia y la técnica: presupone la ausencia de una distinción que ha tenido (y en parte tiene todavía) un peso notable en el debate filosófico, vale decir aquella entre racionalidad científica (neutral respecto de valores, según la célebre tesis weberiana de la avaloración) y racionalidad ética. Es sobre la base de esta distinción que se arraiga la convicción de un insuperable politeísmo de los valores, el cual en el campo moral no puede conducir más que al relativismo y al escepticismo. (Ésta es la herencia del nihilismo, del cual nuestro "pensiero debole" es solamente una caricatura.)

Jonas representa al respecto una alternativa decisiva. Con la ética de la técnica, cuyos contornos él intenta delinear en Technik, Medizin und Ethik ${ }^{33}$, surge el problema de si la misma ciencia de la naturaleza no debe hoy estar sujeta a un vínculo ético. Jonas pone en cuestión el hecho que la ciencia y la técnica pueden continuar siendo exeptuadas de responsabilidad. Lo que ya no vale es propiamente aquel postulado de neutralidad respecto a los valores que caracterizaba a la ciencia y que relegaba todo lo que no parecía "libre de valores" en el ámbito de la esfera de las libres (arbitrarias) decisiones subjetivas. Después de Hiroschima (en la lógica de Jonas sería mejor decir después de Chernobyl, si se pudiese datar este acontecimiento con anterioridad) ningún científico puede continuar durmiendo tranquilamente ${ }^{34}$. La técnica deja de ser una esfera neutral del obrar humano y deviene objeto de la ética.

Aún queriendo seguir a Jonas en este camino, no podemos, sin embargo, hacer menos que preguntarnos si él nos conduce a la meta que se había prefijado: la fundamentación de una ética para la civilización tecnológica. En otras palabras, no se intenta poner en discusión el problema que Jonas formula, sino sobre todo la adecuación de su respuesta. Si se aceptase su

${ }^{33}$ En particular en los ensayos tercero, cuarto y quinto, compilados en el volumen Technik, Medizin und Ethik, cit., pp. 53-108. Véase también H. Jonas, "Warum wir heute eine Ethik der Selbstbeschränkung brauchen?”, en: E. Ströcker (Hrsg.) Ethik der Wissenschaften? Philosophische Fragen, München-Paderborn, W. Fink-F. Schöningh, 1984, pp. 75-86.

${ }^{34}$ Aunque es propiamente en Hiroschima que Jonas ve la "primera demostración de la extrema peligrosidad del poder que la moderna ciencia de la naturaleza ha procurado al hombre". (Así lo formula Jonas en una reciente entrevista "Pläyoder für eine planetarische Zukunft" (1992), en: D. Böhler, R. Neuberth (Hrsg.) Herausforderung Zukunftsverantwortung. Hans Jonas zu Eheren, Münster, Hamburg, Lit. $1993^{2}$, pp. 97-101. 
punto de vista, ¿qué resultado se obtiene a partir de él? Que la ciencia misma presupone una ética y que entonces su libertad de investigación no es absoluta, sino condicionada por la responsabilidad socialmente y moralmente relevante de la ciencia misma. Se trata de una conclusión indudablemente importante, que sustancialmente permite justificar una política de la ciencia más restrictiva y de establecer toda una serie de prohibiciones al desarrollo de la técnica. Nada menos, pero también nada más. Esto es, Jonas muestra solamente que no podemos más dejar a un lado la moral cuando afrontamos los interrogantes establecidos por el actual desarrollo de la técnica, pero con ello él todavía no ha resuelto propiamente el problema de una fundamentación de la ética en la era de la ciencia.

Si también se admite que la simple actividad de investigación de las ciencias naturales ya presupone necesarriamente una ética, con ello no hemos aún dicho nada decisivo en torno al fundamento de la validez de las normas que estamos obligados a seguir para obrar de modo responsable. Por otro lado, Jonas se encuentra en un impasse análogo a aquél en el que cae Apel. Si este último no escapa de la falacia intelectualista, desde el momento que pretende deducir normas vinculantes del obrar moral partiendo de las condiciones de uso de nuestro intelecto, Jonas, por su lado, aún sin caer en la clásica falacia naturalista (en cuanto el ser no es entendido por él como conjunto de hechos neutrales respecto a valores, sino aristotélicamente como un fin en sí mismo, dotado de valor intrínseco), no nos ofrece otra cosa que una mera petitio principii: la "autoafirmación del ser" que debe continuar siendo. Su perspectiva conduce solamente a la pura y simple tutela de la sobrevivencia del género humano sobre la tierra, a la salvaguarda de la incondicionada exigencia "que haya hombres"35. Si Apel con su ética de la comunicación nos presenta una fundamentación lógica de la ética, Jonas cree, en cambio, necesaria una fundamentación ontológica centrada sobre el principio de la defensa de la integridad del ser humano. Ambas se revelan insatisfactorias: la primera por su intelectualismo, la segunda por el dogmatismo de la autoafirmación del ser que difícilmente puede ser puesto a la base de la ética.

Bien entendido, frente a la posibilidad real de su aniquilación con el descubrimiento de la bomba atómica o a la puesta en discusión de su integridad biológica con los inquietantes desarrollos de la ingeniería genética, también la sobrevivencia del género humano adquiere relevancia ética. Y no

\footnotetext{
${ }^{35}$ Cfr. H. Jonasung, Das Prinzip Verantwort, cit., pp. 91-92. La inadecuación de este principio para una fundamentación racional de la ética ha sido subrayada por Apel en el ensayo ya citado (cfr. n. 8) y más recientemente en: K. O. Apel, Etica della comunicazione, cit., en particular: pp. 22-23.
} 
se puede más que compartir la alarma que Jonas lanza frente a las amenazas acarreadas por la biotecnología a la integridad de la especie ${ }^{36}$. Sin embargo, lo que aquí se quiere subrayar es que sobre la base del presupuesto puramente ontológico-teleológico de su ética él puede solamente fundamentar el deber de preservar la vida humana sobre la tierra -una suerte de imperativo quasi-biológico de la conservación- pero aún no un imperativo auténticamente moral. En realidad, ese presupuesto no puede fundamentar el igual derecho que cada individuo tiene a esa sobrevivencia. El problema moral surge todavía propiamente aquí: no "que haya hombres", sino cuáles son las condiciones sobre cuya base deben ser reguladas sus relaciones. Considerada pura y simplemente bajo el perfil biológico, la sobrevivencia de la especie humana en la actual situación de sobrepoblación y de escasez de recursos poría ser asegurada también abandonando a una parte de la población (se piensa en el tercer mundo) a su destino. Antes bien, la perspectiva de salvar a la especie humana y su futuro sacrificando a una parte de ella podría parecer la solución más eficaz no sólo para nuestra especie, sino también para el entero equilibrio ecológico. No pretendo sostener que Jonas estaría dispuesto a aceptar esta cínica perspectiva: él mismo advierte cuan absurdo sería predicar el respeto al ambiente de poblaciones que están muriendo de hambre. Sin embargo, no se puede negar que sobre la base del impertivo "que haya humanidad" dicha perspectiva pueda ser objetivamente justificada o, por lo menos, no excluída categóricamente. En suma, elevar a objetivo ontológico la permanencia de la vida humana sobre la tierra no es suficiente - como en cambio querría Jonas- para fundamentar una ética de la responsabilidad.

Tal fundamentación debe considerar los derechos y los deberes que conciernen a cada individuo. Y aquí, el punto de partida (aunque no necesariamente el de arrivo) puede ser aún la idea kantiana de la reciprocidad, que Jonas, en cambio, rechaza decididamente. Ninguno puede exigir a los otros el reconocimiento de la propia libertad, si él mismo no está dispuesto a hacer lo mismo frente a todos los demás. Es sólo sobre la base de esta absoluta simetría, por la cual yo concedo a los otros solamente aquella porción de mi libertad que los demás me conceden a mí, que se puede fundar un obrar moralmente responsable. Este principio no salva necesariamente a la especie, pero permite instituir una regla que permite la convivencia entre los hombres.

Se podrá replicar que este enfoque no supera los confines "antropocéntricos” que caracterizan a la visión tradicional de la ética que Jonas, en cambio,

\footnotetext{
${ }^{36}$ Véase sobre todo: "Laßt uns einen menschen klonieren? Betrachtungen zur Aussicht genetischer Versuche mit uns selbst" (1982), ahora recogido en: H. Jonas, Technik, Medizin und Ethik, cit., pp. 162-203.
} 
cree necesario superar. Sin empbargo, yo creo que aquella visión tradicional puede ser también ampliada: considerar a la idea de reciprocidad como punto de partida no implica que todos nuestros deberes deban ser reductibles al esquema de un perfecto equilibrio entre dar y recibir. Nada impide pensar que nuestros deberes puedan dilatarse más allá de aquel esquema y conducir a dar a los otros, en determinadas situaciones, más de cuanto ellos pretenden de nosotros, de dar, en suma, más de cuanto podamos recibir. Y una vez ampliada la ética hasta esta idea de solidaridad humana (que supera, pero conserva la concepción precedente) no es difícil extenderla ulteriormente hasta incluir también la idea de una solidaridad interespecífica. Pero ahora no quiero aventurarme sobre este terreno ${ }^{37}$.

La sospecha es que Jonas, a pesar de todos los testimonios en sentido contrario, poniendo como fundamento de su construcción el principio que aquí haya y deba continuar habiendo una humanidad, no hace otra cosa que reconfirmar un punto de vista cuasi-antropocéntrico. Ello me parece que resulta de la posición que asume en torno al problema de la fundamentación de una ética ambiental.

A grandes razgos se puede decir que dos son las tendencias que actualmente se confrontan. Por una parte, hay quien sostiene la necesidad de la protección de la naturaleza sobre la base de la consideración del interés humano. Según esta dirección antropocéntrica, la naturaleza es un bien puesto al servicio del hombre, que resulta necesario tutelar por motivos de utilidad. Por otra parte, hay quien piensa, en cambio, que la naturaleza tiene un valor intrínseco y como tal debe ser respetada en base a su propio derecho. Es sobre todo sobre la base de esta dirección biocéntrica que se ha hablado de "ruptura del antropocentrismo".

Pues bien, la perspectiva de Jonas no parece ser completamente reductible a ninguna de estas dos posiciones. Ciertamente, él critica al utilitarismo antropocéntrico, pero, por otro lado, el "valor en sí" del que él habla no resulta identificable con el "valor intrínseco" de los partidarios de la así llamada "deep ecology" 38 . Para éstos es necesario reinsertar al hombre en la naturaleza, concibiéndolo según una perspectiva holística, como parte

\footnotetext{
${ }^{37}$ Me permito remitir a dos contribuciones mías: P. Becchi, "È possibile una bioetica razionale? Variazioni su temi kantiani”, en: Annali della Facoltà di Giurisprudenza di Genova, XXIII, 1989-1990, fasc. 1-2, pp. 39-70 y P. Becchi, "I doveri dell' uomo nei confronti della natura. Congetture sull' etica di Kant”, en: L. Battaglia (ed.), Etica e ambiente, Torino, Satyagrapha Editrice, 1992, pp. 180-190.

${ }^{38}$ En efecto, Jonas rechaza totalmente la hipótesis de los derechos intrínsecos de la naturaleza que, en cambio caractewriza a tal movimiento. Cfr. al respecto J. Landkammer, "Le domande estreme e le risposte evanescenti di Hans Jonas", en: Filosofía Política, IV, n 2, 1990, pp. 423-429.
} 
del todo orgánico que es la naturaleza. La posición de Jonas al respecto es mucho más ambivalente: parece quedar suspendido entre una concepción monística, según la cual espíritu y materia no serían esferas heterogéneas entre sí y una concepción dualísta, para la cual, por el contrario, el espíritu es autónomo respecto de la materia y no resulta reductible a un epifenómeno suyo. Aunque es cierto que Jonas se inclina por la concepción monística, si el fuese verdaderamente consecuente, entonces no debería atribuir al hombre aquella centralidad (típica de la concepción dualista) que le viene conferida por el principio de la preeminencia de la sobrevivencia del género humano sobre la tierra. Este principio es aceptable sólo si se presupone que el hombre es algo diverso y separado del mundo natural: lo que justamente comporta la aceptación de un punto de vista antropocéntrico ${ }^{39}$. Además, la perspectiva biocéntrica, en el momento que presupone la existencia de un valor intrínseco de la naturaleza, cree, del mismo modo, que existen derechos verdaderos y propios de la naturaleza. Aunque bajo este aspecto, Jonas parece más bien lejano de esta perspectiva, por lo menos si nos referimos a los derechos en sentido jurídico.

Para Jonas no se puede considerar a la naturaleza como a un participante de una relación contractual; no se trataría entonces -como se ha sostenido recientemente ${ }^{40}$ - de pactar un nuevo "contrato natural": la naturaleza no puede tener ninguna obligación con nosotros y, por lo tanto, no puede tampoco tener derechos. Lo que no significa que nosotros no seamos responsables de su cuidado, en realidad nuestro deber se extiende, esta vez unilateralmente, también respecto de la naturaleza. Pero además cuando Jonas insiste sobre la necesidad de una nueva relación con la naturaleza, el centro de su reflexión sigue siendo todavía aquel sujeto único capaz de responsabilidad, que es el hombre.

Ciertamente, la suya es una propuesta de ética global que acarrea tanto al hombre como a la naturaleza, pero el sujeto activo de esta ética sólo

\footnotetext{
39 Sobre esta ambivalencia entre un monismo explícitamente declarado y un dualismo subrepticiamente introducido ha justamente llamado la atención S. Tönnies, "Hans Jonas zwischen Sein und Sollen", en Rechtstheorie, 22 (1991), pp. 370-381.

${ }^{40}$ Por Michel Serres en el volumen Le contract naturel, Paris, Bourin, 1990. Justamente en relación a una pregunta referente a este libro, Jonas observaba en una reciente entrevista: "Por lo que respecta en cambio a la idea de considerar a la naturaleza como un participante de una relación de tipo contractual, debo decir que, a mi juicio, se trata de una idea incoherente desde el punto de vista filosófico (...) Es sujeto de derecho solamente un sujeto que puede elevar reivindicaciones en confrontaciones conmigo y que puede también reconocer mis derechos hacia él, (...) derechos sujetos a un arbitrio por la reciprocidad de los derechos y los deberes. No estando obligada en nuestras confrontaciones, la naturaleza no tiene ni siquiera los derechos que podría tener un sujeto de derecho" (H. Jonas, "De la gnose au 'Princìpe responsabilité'. Un entretien avec Han Jonas", cit. p. 15.
} 
puede ser el hombre llamado ahora a hacerse cargo no sólo de sí mismo, sino también del mundo en el que vive. Quizás es también por esta razón que Jonas, cuando afronta problemas de ética práctica, se concentra otra vez en el hombre. En suma, su ética, como la de Apel, aunque en un sentido distinto, continúa siendo una "ética de la técnica" (y de la incidencia de ella sobre la vida de los hombres), con todos los límites que, como se ha tratado de mostrar, esta fórmula contiene.

(Traducción Alberto M. Damiani) 
$\triangle \quad$ DOXA 25 (2002) 